Uluslararası Sosyal Bilgilerde Yeni Yaklaşımlar Dergisi, 2021, 5(1), 294-304

International Journal of New Approaches in Social Studies, 2021, 5(1), 294-304

\title{
Filoloji Çalışmalarında Gastronominin İzleri: Ermeni Harfli Kıpçak Türkçesi Metinlerinde Yeme İçme
}

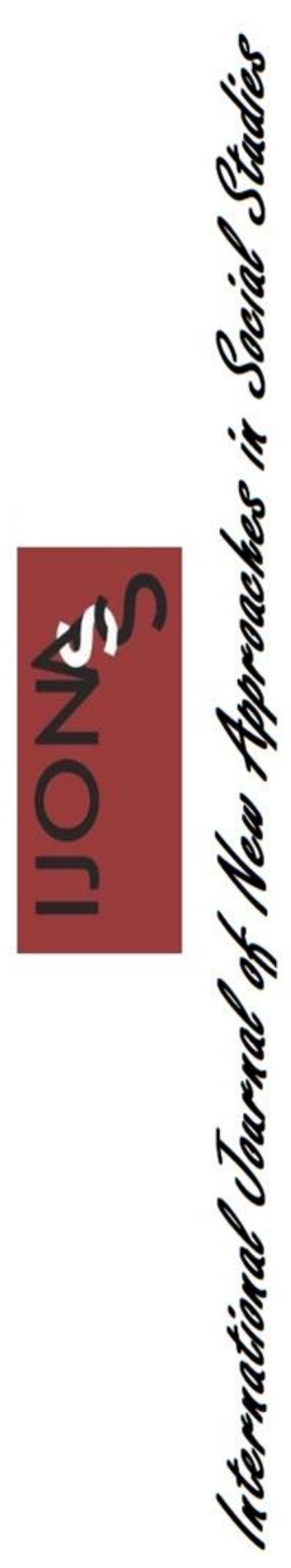

\author{
Zeliha TUĞUZ ${ }^{*}(\mathbb{D})$
}

Gönderilme Tarihi: 02 Haziran 2021

Kabul Tarihi: 21 Haziran 2021

DOI: $10.38015 /$ sbyy. 946849

\begin{abstract}
Öz:
İnsanın en temel ihtiyacı olan yeme içmeyi merkez alan gastronomi; kısaca mutfak gelenek ve göreneklerini içerecek biçimde yiyecek hazırlama, sunma ve yemenin bilimidir. Özellikle son yillarda büyük ilgi gören gastronomi; kimya, fizik, biyoloji, psikoloji, sosyoloji, tarih, filoloji, antropoloji, ekonomi, pazarlama, yönetim, işletmecilik gibi fen ve sosyal bilimlerden yararlanan geniş kapsamlı bir disiplindir. Evrensel bir bakış açısına sahip ancak ulusal kaynaklardan, köklerden beslenen gastronominin yiyecek üretimi, yiyeceklerin üretildiği araçlar, yiyeceklerin depolanması, taşınması, işlenmesi, pişirilmesi, yemeklerin usulü, lezzeti, yemekler hazırlanırken kullanılan özel eşyalar, yiyeceklerin kimyası, sindirimi, fizyolojik etkileri, yiyeceklerin toplumdaki gücü ifade etmesi ve statüyü belirlemesi, yiyeceklerin dinî, sosyal, toplumsal ve kültürel yönü, yiyeceklerin halk hekimliğiyle, büyücülükle ve törenlerle olan ilişsisi gibi konularına katkı sağlayacak verileri Ermeni harfli Kıpçak Türkçesi metinlerinde tespit etmek mümkündür. Araştırmanın örneklemi olarak seçilen Ermeni harfli Kıpçak Türkçesi metinleri, 1521-1699 yılları arasında, Karadeniz'in kuzeyinde, Ermeni harfleri kullanılarak din, tarih, hukuk, edebiyat, dil, kimya gibi birçok farklı konuda Kıpçak Türkçesi ile yazılmış yaklaşık 30 bin sayfadan oluşan metinleri kapsamaktadır. Yöntem olarak tarama modeli kullanılan çalışmada Ermeni Harfli Kıpçak Türkçesi metinleri incelenmiş; gastronomi ile ilgili bulgular, yorum ve tartışmada paylaşılmıştır. Toplumların dünya görüşleri, hayat felsefeleri, dinî normlarl, sosyal kaideleri yeme içme alışkanlıkları üzerinden takip edilebildiğinden Türk toplumunun yeme içme yaşantılarını ve bu yaşantıların değişim ve gelişimini ortaya koyan çalışmalar gastronomi ile ilgili yapılan ve yapılacak çalışmalara güç katacaktır.
\end{abstract}

Anahtar Kelimeler: Ermeni harfli Klpçak Türkçesi metinlerinde yeme içme, Ermeni harfli Kıpçak Türkçesi, filoloji-gastronomi ilişkisi.

\begin{abstract}
:
Gastronomy focuses on eating and drinking, which is the most basic need of human beings, in short, it is the science of preparing, serving and eating food in a way that includes culinary customs and traditions. Especially in recent years, gastronomy has attracted great attention. It is a comprehensive discipline that makes use of science and social sciences such as chemistry, physics, biology, psychology, sociology, history, philology, anthropology, economics, marketing, management and business administration. Gastronomy has a universal perspective but draws strength from national sources. It is possible to identify data that will contribute to issues such as food production, the storage, transportation, processing and cooking of food, the method of food, its taste, the special items used, the chemistry of food, its digestion, its physiological effects, the determination of the power and status of food in society, the
\end{abstract}

${ }^{1}$ Mersin Üniversitesi, Türkiye, ORCID ID: 0000-0003-0977-8858
${ }^{*}$ SorumluYazar (Corresponding Author): zelihatuguz@ gmail.com 
such as its relationship with folk medicine, witchcraft and ceremonies in the texts of Kipchak Turkish with Armenian Letters. The texts in Kipchak Turkish with Armenian Letters, chosen as the sample of the research, include approximately 30 thousand pages, written in Kipchak Turkish between 1521 and 1699, on many different topics such as religion, history, law, literature, language, chemistry, using Armenian letters, in the north of the Black Sea. The scanning model was used as the method and Kipchak Turkish texts with Armenian letters were examined, the findings related to gastronomy were shared in the comments and discussion. Since the worldviews, the philosophy of life, religious norms and social rules of the societies can be followed through their eating and drinking habits, studies that reveal the eating and drinking experiences of the Turkish society and the change and development of these experiences will add strength to the studies on gastronomy.

Keywords: Eating and drinking in Kipchak Turkish texts with Armenian letters, Kipchak Turkish with Armenian letters, philology-gastronomy relationship.

\section{GíRiş}

Her ne kadar "gastronomi” terimi ilk olarak 19. Yüzyılın başında Fransa'da bir şiirin başlığında (Seyitoğlu \& Çalışkan, 2018: 524) geçmiş olsa da bu bilgi, gastronominin daha önceki yüzyıllarda olmadığı anlamına gelmemektedir. Bu alanda yapılan çalışmalara bakıldığında ilk olarak "gastro" mide ve "nomos" kanun şeklinde kavram kökenleri verilmektedir ancak bu açıklama terimin etimolojik açılımını vermeye bile yeterli değildir. Gastronmi, mide + kanun açıklamasının çok daha ötesindedir.

Yenilen ve içilen her şeyi kapsayan geniş kapsamlı bir disiplin olan "gastronomi" terimi, yiyecek ve içecekten en iyi şekilde zevk almayı, yiyecek ve içecekle olan kültürel bağı koruyacak şekilde yemek pişirmeyi, hazırlamayı; yiyecek üretimini, yiyeceklerin üretildiği araçları; yiyeceklerin depolanmasını, taşınmasını, işlenmesini, pişirilmesini; yemekleri ve usulü; yiyeceklerin kimyasını, sindirimini, fizyolojik etkilerini; yiyecek seçimlerini, gelenek ve görenekleri kapsamaktadır (Seyitoğlu \& Çalışkan, 2018: 524).

Geçmiş dönemlerde gastronomiye ait tüm veriler ancak filolojik metinlerde tanıklanabilmektedir. Filoloji sadece geçmişe dönük verilerin kaydında değil, aynı zamanda farklı disiplinlerin sonraki nesillere aktarımını sağlayan en önemli bilim dalıdır. Sözlü edebiyatın ancak izleri sonraki dönemlerde takip edilebiliyorken yazılı edebiyat ve yazılı dil ürünleri tarihe ve daha birçok bilime birinci elden tanıklık eder. Sadece tanıklık etmekle kalmaz, bu bilgi birikimini sonraki nesillere aktarır, gelişmesine, ilerlemesine katkıda bulunur.

Araştırmanın örneklemi olarak seçilen Ermeni harfli Kıpçak Türkçesi metinleri, 1521-1699 yılları arasında, Karadeniz'in kuzeyinde, Ermeni harfleri kullanılarak din, tarih, hukuk, edebiyat, dil, kimya gibi birçok farklı konuda Kıpçak Türkçesi ile yazılmış yaklaşık 30 bin sayfadan oluşan metinleri kapsamaktadır (Pritsak 1998: 123; Garkavets \& Hurşudyan 2001: 587). Ermeni harfli Kıpçak Türkçesi, köken olarak Kırım bölgesinin Kıpçak-Polovets dillerine bağlıdır. Yapı olarak da Karaimcenin Trakya ağzına, Kumancaya, Kıpçak Urumcasına ve Kırım-Tatar dağ şivesine benzemektedir (Garkavets, 2002: 12). Çok zengin bir içeriğe sahip bu metinler günümüzde Viyana Mekhitarist Manastırı, Viyana Millî Kütüphanesi, Venedik Mekhitarist Kütüphanesi, Paris Millî Kütüphane, Wroclaw Ossolineum Kütüphanesi, Krakow Chartorysky Müzesi, Leiden Üniversite Kütüphanesi gibi Avrupa ve Asya'nın kadim kütüphanelerinde muhafaza edilmektedir. Türkolojide büyük bir hazine olan 
bu metinlerin keşfi ve bilim dünyasına duyurusu geç olduğu için bu alanda yapılmış çalışmalar diğer dönemlere göre oldukça az sayıdadır.

Oldukça hacimli olan Ermeni harfli Kıpçak Türkçesi metinleri incelenirken bu alandaki en son ve en kapsamlı çalışma olması sebebiyle Aleksandr Garkavets'in Ermeni harfli Kıpçak Türkçesi eserlerinin söz varlığını içeren eserleri "Kıpçakskoe Pismennoe Nasledie I", "Katalog i Teksti Pamyatnikov Armyanskim Pismom ve Kıpçakskoe Pismennoe Nasledie II", "Pamyatniki Duhovnoy Kulturi Karaimov, Kumanov-Polovtsev i Armyano- Kıpçakov ve Katalog i Teksti Pamyatnikov Armyanskim Pismom ve Kıpçakskoe Pismennoe Nasledie III" esas alınmıştır.

\section{INCELEME}

Filoloji çalışmalarına bakıldığında gastronomi daha çok metinlerde geçen yiyecek içecek adlarının ya da bu adlarla ilgili sözcüklerin leksikolojik sınıflandırılmasına hapsolmuştur. Hâlbuki söz konusu metinlerde eşdizimlilik (collocation) yöntemiyle sözcüklerin sadece sözlük anlamı değil bağlamı da verildiğinde sözcüklerin kültürel, sosyal, dinî, ticari, siyasi anlam alanları da sergilenmiş olmaktadır.

Yöntem olarak tarama modeli kullanılan çalışmada Ermeni harfli Kıpçak Türkçesi metinlerindeki yemek adları, yemek malzemeleri, yemek tarifleri, yiyeceklerin özellikleri, yiyecekler hazırlanırken kullanılan özel eşyalar, yiyeceklerin tadı, yiyeceklerin kimyası, yiyecek sektörü, yiyeceklerin niteliği ve niceliğinin toplumsal gücü, yiyeceklerin halk hekimliğindeki yeri, yiyeceklerin dini, sosyal, toplumsal ve kültürel yönü ile ilgili veriler aktarılmaya çalışılmıştır.

\section{Ermeni Harfli Kıpçak Türkçesiyle Yazılan Metinlerde Yemek Adları, Yemek Malzemeleri, Yemek Tarifleri}

Söz konusu metinler hacimce çok zengin olduğu için sadece yiyecek adları bile tez yapılacak kadar malzeme ihtiva etmektedir. Bu sebeple sınırlı olan bu çalışmada sadece konu başlıkları ile ilgili fikir verecek seçili örnekler paylaşılmıştır.

Tutmaç (III, 1513) "tutmaç", yalamah (III, 1628) "lapa", aşlıh̆ suvu (III, 159, 1333) "tahıl çorbası", bişirgen aşlıh bile bal (III, 209) "bal ile haşlanmış tahıl”, bişirgen aş (III, 152) "pişirilmiş yemek (çorba)", bişken aş (III, 152) "pişmiş yemek (çorba)", semiz aşlar (III, 326) "yağlı yemekler", ah un (II, 818) "beyaz un", arış unu (II, 698) "çavdar unu”, açı hamur (I, 570, 571) "ekşi hamur", taje saryag (II, 769, 775) "taze tereyağ", küyük tuz (III, 710) "yanmış tuz", açıtmah (III, 27) "maya", kesek balıh̆ şişlegen (I, 569) "şişe geçirilmiş (bir) parça balık", bir kesek toyuz eti (II, 344) "bir parça domuz eti", limon suvu (III, 342, 778, 1334) "limon suyu”, hoy süti (I, 1062) "koyun sütü”, sütü eçkilerniך (I, 816) "keçilerin sütü”, bir kesek çıbal (I, 37) "bir parça bal, hurutkan borla (III, 315, 367, 902) "kurutulmuş üzüm”, huru incir (III, 159, 901) "kuru incir"...

Yemek tariflerinde sadece tariflerle ilgili verilere değil aynı zamanda o yemeğin hangi millete/kültüre ait olduğu bilgisi de verilmiştir: Kazbin, tatl, kökten ener, ya şerpet tatll, ya çibal, ya Kaġajat ulusunda bolur, ya nede tatlı bar, ya hurma, ya şeker, ki çıbaldan da tüvüden tüzelir. (II, 849; III, 662, 721, 1532) "Helva, tatl, cennetten iner, tatlı şerbet ya da bal, Kaġajat ulusunda olur, içinde ne tatlı, hurma ne de şeker var; baldan ve darıdan yapılır." 
Özellikle bazı yemekler yapılırken dikkat edilecek unsurlar ayrıca belirtilmiştir: barçanı ezip igi sirke bile olivaga qatıştırma (III, 1272) "hepsini ezip iyi sirke ile zeytinyağına karıştırmak". Çah ki uprazicca bolgay zârnkalar da bolgay neçik bürüşken çiçek ya burç. (III, 364, 383) "Taneler buruşuk çiçek ya da karabiber gibi olana kadar kızaracak."

Yiyeceklerin yanında içecek tarifi ya da içeceklerin özellikleri de verilmiştir: Raḩı, huvatlı içki, ne bile esirme bolur adam, haysı ki hurmadan, da aşlıhtan, da her türlü urluhlardan eterler. (II, 874) "Rakı, kuvvetli içki(dir), insan onunla sarhoş olur, hurmadan, tahıldan her türlü tohumdan yapılır." Bizge osoblivı lezetni yetişken çiyeden etti. (II, 484) "Bize özel lezzeti yetişkin vişneden elde etti."

\section{Ermeni Harfli Kıpçak Türkçesiyle Yazılan Metinlerde Yemekler Hazırlanırken Kullanılan Özel Eşyalar, Yiyeceklerin Lezzeti, Yiyeceklerin Kimyası}

Yemeğin yapım aşamasında dikkat edilecek unsurlar ve kullanılan malzemelerin yanı sıra kullanılan mutfak eşyalarını tanıtan cümlelere örnek: Stupa, ki tüvü ya özge neme ezerler ya töverler/ki içine aşlıh töverler. (III, 441) "Dibek içinde darı ya da bunun gibi şeyler ezerler ya da döverler."

Metinlerde aşlarnı jmakı (III, 153, 1368) "yemeklerin lezzeti” ve yaḩşı aş (I, 231) "güzel yemek" oldukça önemlidir. Taḩılnı 408) "tahılın dolgunluğu", tatl yemeh (I, 266) "lezzetli yemek", yemeh tatlı da bagalı (II, 185) "lezzetli ve pahalı yemek", nurnuy hısılgan tatl suvu (II, 814; III, 1028, 1334) "ezilmiş narın tatlı suyu", ferâhlatuçı içki (I, 128) "ferahlatıcı içki", sövüklü içki (I, 128) "sevilen içecek" metinlerde her zaman olumlanmışken yalayaç bürtük (III, 1629) "sade tahıl", bişmegen açı borla (III, 315) "olgunlaşmamış ekşi üzüm”, aş buzulgan (III, 152) "bozulan yemek", yemeh aruvsuz (II, 284) "temiz olmayan yemek", yemeh nikçemnı (II, 185) "sıradan yemek", yemeh hrubı (II, 185) " basit yemek", açı suv (III, 1400) "acı su, içilmez su”, süt kesilgen (II, 760) "kesilen süt” tercih edilmeyen yiyeceklere örnektir.

Yiyeceklerin sadece tadı değil kimyası ile ilgili de bilgiler verilmiştir: Bilmes misiz, ki azgına açı hamur barça nemeni açıtır? Arıtınız keri eski açı hamurnu, ki bolgaysiz yẹi yaratılgan, ne türlü ki siz açıtmagan. (III, 27) "Azıcık ekşi hamurun her şeyi ekşittiğini bilmez misiniz? Sizin için yeniden yaratılacak sizi ekşitmeyecek eski ekşi hamuru temizleyiniz. Azgına sirke bütün içkini sirkeletkey. (I, 174) "Azıcık sirke bütün içkini sirkeletir (ekşitir).”

\section{Ermeni Harfli Kıpçak Türkçesiyle Yazılan Metinlerde Yemek Sektörü}

Yemek sadece besini oluşturan kimyasal maddeler olarak ve organizmanın canlılığını sürdürmesi için taşıdığı önem açısından değerlendirilemeyeceği için (Beşirli, 2010: 168) temininden tüketimine kadar yemekle ilgili oluşumlar gastronominin çalışma alanına girmektedir. Yemeğin iyi olması malzemelerin iyi yetiştirilmesiyle doğru orantılıdır. Ermeni harfli Kıpçak Türkçesi metinlerinde özellikle bahçecilikle ilgili bölümlerde gida yetiştiriciliği ve bunun en iyi nasıl olacağı ile ilgili bilgiler verilmiştir: Zera eger ki sen kiyik maticasından

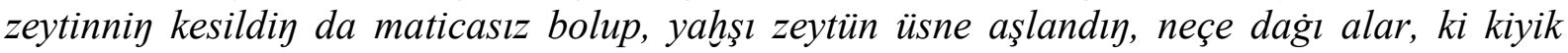
dügüller, aşlangaylar kendilerinin zeytünü üsne. (III, 1779) "Eğer sen yabani zeytinin budağından kesip budağı olmayan, yabani olmayan iyi bir zeytin aşılarsan o zeytinin üstüne aş1lanır." Igi almalar da armutlar bu türlü biter yandralardan. (I, 956) "Tohumlardan elde edilen iyi elmalar ve armutlar bu şekilde büyür." Şeftelü tereki anınki şçipadan söveksiz şeftelüler tuhurur, erük tereki alay oh söveksiz erükler tohurur. (III, 1301) "Onun aş11 şeftali ağacından çekirdeksiz şeftali, aynı şekilde erik ağacından çekirdeksiz erikler çıkar.” 
Metinlerde yemeğin ana unsurlarının yetiştirilip sofraya getirilişine kadar hizmet eden pek çok meslek erbabı ile ilgili veriler bulunmaktadır:

Hahrada 3 trabizon aşlıh da bir boçka arış (III, 792, 1500) "girişte üç fiçı Trabzon buğdayı ve bir fiç1 çavdar"1, 1 tavuh 80 ahça, 1 yumurtha 8 ahça, 1 sogian 5 ahça, 1 sarımsah 10 ahça (I, 565) "bir tavuk seksen akçe, bir yumurta sekiz akçe, bir soğan beş akçe, bir sarımsak on akçe"ye, baş sarımsah 1 hroş (I, 564; III, 231) "baş sarımsak 1 groş”a satan bezirgân (III, 264) "tüccar", satkan/satuçı (III, 1246) "satıcı"larla birlikte aşçı (III, 157) "aşçı", aşçı başı (III, 157) "aşçıbaş1", çörehçi (III, 404) "çörekçi” ötmekçi (III, 1103) "ekmekçi, firıncı", suv aluçılar (III, 88) "sucular", suv taşıgan (III, 1334, 1397) "su taşı1ıı”, borla kesüçi (III, 687) "üzüm toplayıcısı", borla baģçaçısı (III, 315) "asma bahçıvanı”, yemiş keltirüçi (III, 674, 1689) "meyve getiren, meyve nakliyesi yapan", yemiş sahlavuçıları (III, 1689) "meyve (bahçesi) bekçileri" bahçaçı/ baģçaçı (III, 208, 203) "bahçıvan", borlaçı (III, 316) "bağcı", çaluçı/çalıçı (III, 366) "ekin biçen, orakçı", çayahavuçı (III, 373) "sulayıcı", suvaruçı (III, 373) "sulayıc1", tiyirmençi/ tıyermençi/ tıyırmençı (III, 1453, 1462, 1464) "değirmenci"... yeme içme sektörüne hizmet eden ve doğal olarak katkı sağlayan meslek erbaplarıdır.

\section{Ermeni Harfli Kıpçak Türkçesiyle Yazılan Metinlerde Yiyeceklerin Toplumdaki Gücü İfade Etmesi ve Statüyü Belirlemesi}

Tarih boyunca bazı gıdalar, dönemin ekonomik ve sosyal şartlarına göre zenginliğin ve gücün sembolü olmuştur. Bu gidalara sahip olanların toplumsal statüsü onlardan yoksun olanlara kıyasla daima daha iyi durumda olmuştur. Bunlardan en önemlisi baharattır. Besin, güç ve zenginlik ilişkisinde baharatların çok önemli bir yeri vardır. Baharat tüketimi, kişinin zenginlik, güç ve cömertliğini göstermesinin ve bunu kanıtlamasının bir yoludur. Baharatlar hediye olarak verilir, başka değerli mallarla birlikte miras olarak bırakılır ve bazen para olarak kullanılır. Tüm bu yönleriyle baharat besin ve güç ilişkisinde insanlık tarihine yön vermiş besin maddelerinden biridir (Öztek, 2019: 17): fruktlar hem bahar... bir hapçuh içine rujnıy bahar (III, 206) "meyveler ve baharat... bir kese içinde farklı baharatlar", 24 Ilôv kameni burç (III, 652) "yirmi dört Lviv kameni karabiber", eki fund" burç da eki funt kımen (III, 532) "iki funt karabiber, iki funt kimyon", birer ulu oha zafran her uzolgine içine (III, 1572) "Her çıkının içinde birer büyük okka safran”...

Yeme içmenin niceliği ve niteliği her toplumda gücün sembolü olmuştur. Ermeni harfli Kıpçak Türkçesi metinlerinde de kaliteli etler, baharatlı, hoş kokulu yiyecekler, şekerli içecek ve yiyecekler yüksek zümreye has yiyeceklerdir. Yiyeceklerin statü gösterdiği yani sembolik

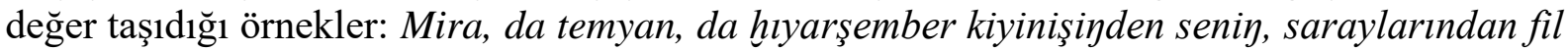
söveklerinden, haydan ki ferâhlattılar seni hızları hanlarnıy hörmetke. (I, 49) "Tütsü bitkisi, kekik ve hıyarşembe giyiminden, fildişinden saraylardan hanların kızları sana hürmet ederek onu mutlu ederler." Da haysı yemeh nikçemni, neçik tir sogian, hıyar, sarımsah da özge hvastlar, haysı pragnut kliy ediler cuhutlar! (II, 185) "Yahudiler soğan, hıyar, sarımsak ve başka kendiliğinden yetişenler gibi değersiz yemekleri arzu ediyorlardı."

Metinlerde bazı yemekler vardır ki en düşük statüyü temsil etmektedir: Yalamah, ki itke berirler. (II, 678) “Lapayı ite verirler.” Bazı milletlerin yemek kültürünün yerildiği cümlelere

\footnotetext{
${ }^{1}$ fund/funt, eski dönemlerde Rusya, Belarus, Ukrayna topraklarında kullanılan ağırlık birimi. 1 funt: 409,5 gram; 1/40 pud (pud, eski dönemlerde Rusya, Belarus, Ukrayna topraklarında kullanılan ağırlık birimi); 32 lota (lota, eski dönemlerde Rusya, Belarus, Ukrayna topraklarında kullanılan ağırlık birimi); 96 zlotnika (zlotnika, eski dönemlerde Rusya, Belarus, Ukrayna topraklarında kullanılan ağırlık birimi)
} 
örnek: Parsiniy tutmaçı artıh̆tır anarzÿan tumdan, ese. (I, 174) "Farisilerin tutmacı kutsallığın değersizliğinden daha iyidir."

\section{Ermeni Harfli Kıpçak Türkçesiyle Yazılan Metinlerde Yiyeceklerin Dini, Sosyal, Toplumsal ve Kültürel Yönü}

İnanç sistemleri, kendilerine mensup toplumların yeme içme alışkanlıklarını yeniden düzenlemiştir ancak bu düzenlemeler daha çok yasaklar biçiminde kendisini göstermiştir. Örneğin Hristiyanlığın pek çok mezhebinde olduğu gibi nisan ayının ikinci pazar günü İsa'nın yeniden doğuşunun kutlandığı Paskalya'dan hemen önce "kutsal hafta" diye bilinen hazırlık evresinde et ve balık tüketilmesi yasaklan büyük perhizdeki yeme içme ritüellerini metinlerde tespit etmek mümkündür.

Evet ol zamannıy araçnortları k'arozel etiyir ediler keri bolma anıjkibik aşlardan oruç künlerinde, aytıp, ki balıh artıhtır, ne ki nab'al, zera ki balıh tügel tiridir, da nab'al dügüldür tiri, yohsa aşlarından tirilernindir saġırmah. (I, 586) "Evet, o zamanın psikoposları oruç günlerinde bunun gibi yiyeceklerden geri durulmasını söyledi; balık süt ürünleri gibi yasaktır, çünkü balık tamamen canlıdır ve süt ürünleri canlı değildir, ama yiyeceklerden süt ürünleri

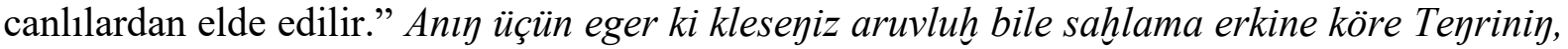
keri boluyuz neçik saġırmahlardan, alayoh balıhtan da. (I, 586) "Tanrı'nın iradesine göre (orucunuzu) kutsallıkla muhafaza etmek isterseniz balıktan olduğu gibi süt ürünlerinden uzak

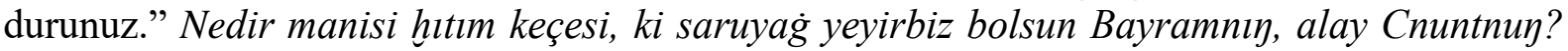
(I, 272) "Yoksunluk gecesinin anlamı nedir çünkü bayramdan (Paskalya'dan) ve dahi Noel'den sonra tereyağı yeriz." Eger sahlamasa, [buzsa] aruv oruçnu balıh̆ yemeh bile, cimrilik bile ya borniglih bile, ol Juta bile hiynalmah kerek tamuhta. (I, 164) "Eğer kutsal orucunu balık yiyerek cimrilikle, zinayla bozsa o Yehuda ile cehennemde eziyet çekmesi gerek."

Türk dili tarihinin tüm dönemlerinde kutsallık içeren tuz yine ilk dönemlerden itibaren kutsallık içeren ekmek ile birlikte kullanılarak toplumsal ilişkilerde dostluğun, yapılan iyiliğin nişanesi olmuştur (Samsakç1, 2007: 190). Bu kutsal yiyeceklerin ikili kullanımı toplum ilişkilerinde bir hak olarak algılanmış ve bu ikilinin inkârı nankörlük ifadesi taşımıştır. Metinde bunu tanıklayan örnekler: tuz-ötmekni ayama (III, 1518) "tuz ekmek (hakkını) "inkâr etmek". Ol kişiler da calatlar menim tuz-ötmekimni unutmadılar. (I, 178) "O kişiler ve cellatlar benim tuz ekmeğimi unutmadılar."

Türk kültüründe kendisine emanet edilen kişinin bakımını en iyi derecede yapmak kişinin önemli sorumluluklarından biridir. Emanet edilen kişinin en iyi şekilde beslenmesi, ona en iyi yiyeceklerin ikram edilmesi de bunun en iyi göstergesidir: Ki işittim men bu avaznı Teyrilerimden, aldım men hardaşım og̉lun 1 yaşına, kiydirdim anı türlü-türlü kamhalar içine, da saldım boyuna altın-inci, neçik han oġlunuy, içirdim da yedirdim anı barça süt bile, da haymah bile, da çiybal bile. (I, 174) "Ben bu sesi tanrılarımdan işittim, kardeşimin oğlunu bir yaşındayken aldım, ona türlü türlü ipek kumaşlar giydirdim, boynuna altın inci taktım, onu hep sütle, kaymakla, balla yedirdim içirdim.”

Kişinin sosyal sorumlulukları anlatılırken bile yeme içme unsurları kullanılarak anlatıma güç kazandırılmıştır: kensiniๆ ötmek yevüçüsü (I, 760) "bakmak zorunda olduğu kişiler”. 


\section{Ermeni Harfli Kıpçak Türkçesiyle Yazılan Metinlerde Yiyeceklerin Halk Hekimliği, Büyücülük ve Törenlerle Olan Illişkisi}

Metinlerde yeme içmeyle ilgili köp aşlardan çatlama (III, 152, 730) "çok yemekten çatlamak (mide fesadı geçirmek)", açig̀lanmah (III, 21) "zehirlenmek", zehirlenmeh (III, 1774) "zehirlenmek" gibi hastalıkların haricinde gastronominin halk hekimliği ile olan ilişkisine tanıklık eden Haysı inanır, yeme barçanı, da kim hastadır, pancar yesin. (III, 825) "Her kim her şeyi yiyebildiğine inanıyorsa ve kim hastaysa pancar yesin." gibi verilerin yanı sıra büyücülük terimi olan arpa salmah (II, 708; III, 136, 1232) "arpa atmak" gibi ifadeler tanıklanmıştır.

Kültürün önemli bir parçası olan tören ve ritüellerdeki yeme içme adetleri, bir topluluğu diğerlerinden ayıran unsurlar barındırmaktadır. Örneğin ölen kişinin gittiği yerde daha iyi muamele görmesi ve kalanların onu iyi hatırlaması için verilen can aşı (III, 90, 934) "cenaze yemeği”, kişinin yine dinî amaçlarına yönelik gerçekleştirdiği canı üçün aş bermeh (III, 152) "hayrına yemek vermek", özel ya da kutsal günlerde verilen ulu aş (III, 153) "bayram yemeği, tören yemeği” metinlerde tanıklanmıştır.

\section{BULGULAR YORUM VE TARTIŞMA}

Ermeni Harfli Kıpçak Türkçesi metinlerinde sadece "ekmek" sözcüğüne bakıldığında bile $a c ̧ ı$ ötmek (III, 541) " mayalı ekmek", açıtkan ötmek (III, 27) "mayalı ekmek”, açısız ötmek (III, 26, 27, 1059) "mayasız ekmek", açıtmagan ötmek (III, 27) mayasız ekmek, bir kesek ötmek (II, 271) "bir parça ekmek", huru ötmek (II, 341) "kuru ekmek", yarım ötmek (III, 19) "yarım ekmek" gibi temel gıda anlamlarının ötesinde; Ne hadar eger yeseyiz bu ötmekni da ayahnı

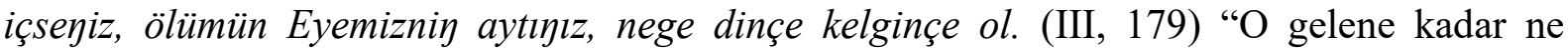
zaman bu ekmeği yeseniz ve şarap içseniz Rabb'imizin ölümünü anlatınız." gibi cümlelerle dini inanışlarda; Ötmek u mereloc nşsanagdır ölünüy ilgeri kelmeki. (III, 609) "Ekmek ve sadaka (dağıtmak) ölünün ileri gelenlerden olduğunun göstergesidir.” gibi cümlelerle kültürel

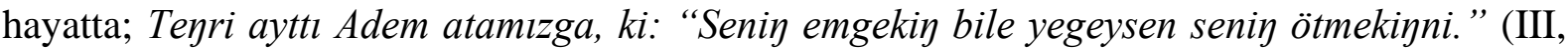
33) "Tanrı Adem atamıza 'Ekmeğini emeğinle yemelisin (kazanmalısın).' dedi." gibi cümlelerle sosyal normlarda yeme içmenin izlerini sürebilmekteyiz.

Gastronomi, evrensel bir bakış açısına sahiptir ancak ulusal kaynaklardan, köklerden beslenir. Metinlerde tespit edilen türk çetlevük (III, 1525) "Türk findığı", Türk hazanı (III, 839) "Türk kazanı", Türkte 70 taylerlih zafran (III, 1758) "Türklerden (alınan) yetmiş taylerlik safran" gibi ifadeler filoloji çalışmalarındaki tespitler sonucu millî unsurların gün yüzüne çıkmasını ve kayıt altına alınmasını sağlamaktadır.

Filoloji-gastronomi alanlarının disiplinler arası çalışmaları ele alındığında literatürde belli dönem ya da belli kültürlerde/milletlerde yeme içme ile ilgili olan sözcük türleri ve bunlarla ilgili morfolojik, etimolojik çalışmalar anlaşılmaktadır. Klasik filoloji çalışmalarındaki yiyecek içecek adlarının sınıflandırılması bu anlamda yeterli olmadığından gastronomi ile ilgili verilerin sadece leksikolojik birimler olarak tek başına değil, bağlam içinde de değerlendirilmesi gerekmektedir. Verilerin bağlam içinde değerlendirilmesi, belli bir alandaki birbiriyle ilişkili sözcüklerin bu ilişkileri göstermesi bakımından oldukça önemlidir. Genelde filoloji çalışmalarında inceleme ya da tanıtma metinlerinin sonunda söz varlığını içeren alfabetik dizin verilmektedir. Disiplinler arası çalışmalara güç katması için alfabetik dizinin yanında bağlamsal dizin verilmesi gelecek araştırmalar için sunulan önerilerden biridir. 
Ermeni harfli Kıpçak Türkçesi metinleri incelendiğinde sadece iyi yiyecek ve yemek tarifleri değil; yiyecek üretimi, yiyeceklerin sevki ve depolanması, yiyeceklerin kimyası, yiyecek seçimleri, yiyecek ve içecekle olan kültürel bağ, yiyecek içeceğe bağlı dinî normlar gibi unsurları tespit etmek mümkündür. Hatta tarihî dönem metinlerinde tanıklanmayan habartkan

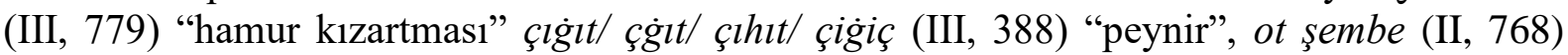
"hıyarşembe otu", şişlik (III, 1355) "kebaplık (et)", yegenliḩ/yemgenlih (III, 1686) "yemek" gibi gastronomiye ait söz varlıklarını da tespit etmek mümkündür.

\section{SONUÇ}

Önceleri bedenin temel ihtiyaçlarını karşılamak adına tüketilen besin, zaman içerisinde hem insanı kültürel bir varlık haline dönüştürmüş hem de kendisini bir kültür öğesi haline getirmiştir. (Öztek, 2019: 196) Bir milletin yaşama kültürü kapsamında değerlendirilebilecek temel unsurlardan en önemlisi yeme içme olduğu için gastronomi ile ilgili her kayıt, her veri bu alanda yapılacak çalışmaları bir adım daha ileriye götürecektir.

Gastronomi, sadece toyma yemeh-içmeh bile (I, 294) "yemek içmekle doymak" değildir. Gastronominin yiyecek üretimi, yiyeceklerin üretildiği araçlar, yiyeceklerin depolanmas1, taşınması, işlenmesi pişirilmesi, yemeklerin usulü, lezzeti, yemekler hazırlanırken kullanılan özel eşyalar, yiyeceklerin kimyası, sindirimi, fizyolojik etkileri, yiyeceklerin toplumdaki gücü ifade etmesi ve statüyü belirlemesi, yiyeceklerin dinî, sosyal, toplumsal ve kültürel yönü, yiyeceklerin halk hekimliğiyle, büyücülükle ve törenlerle olan ilişkisi gibi konulara katkı sağlayacak verileri söz konusu metinlerde tespit etmek mümkündür.

Toplumların dünya görüşleri, hayat felsefeleri, dinî normları, sosyal kaideleri yeme içme alışkanlıkları üzerinden takip edilebildiğinden Türk toplumunun yeme içme yaşantılarını ve bu yaşantıların değişim ve gelişimini ortaya koyan çalışmalar farklı disiplinler ile ilgili yapılan ve yapılacak çalışmalara güç katacaktır.

\section{KISALTMALAR}

I. Kıpçakskoe Pismennoe Nasledie I, Katalog i Teksti Pamyatnikov Armyanskim Pismom

II. Kıpçakskoe Pismennoe Nasledie II, Pamyatniki Duhovnoy Kulturi Karaimov, Kumanov- Polovtsev i Armyano- Kıpçakov

III. Kıpçakskoe Pismennoe Nasledie III, Kıpçakskiy Slovar po Armyanopismennım Pamyatnikam XVI-XVII Vekov

\section{KAYNAKÇA}

Beşirli, H. (2010). Yemek, kültür ve kimlik. Millî Folklor. 11 (87), 159-169.

Çetin, A. (2006). Memluk devletinde yemek kültürüne genel bir bakış. Millî Folklor. 72, 107-117.

Garkavets, A. \& Hurşudyan, E. (2001). Armenian-Qypchaq psalter written by Deakon Lussig from Lviv 1575/ 1580. Desht-i Qipchaq.

Garkavets, A. (2002). Kıpçakskoe pismennoe nasledie , katalog i teksti pamyatnikov Armyanskim pismom. Deşti-i-Kıpçak.

Garkavets, A. (2007). Kıpçakskoe pismennoe nasledie ıl, pamyatniki duhovnoy kulturi Karaimov, Kumanov- Polovtsev i Armyano-Kıpçakov. Kasean Baur. 
Garkavets, A. (2010). Kıpçakskoe pismennoe nasledie ııl, Kıpçakskiy Slovar po Armyanopismennım pamyatnikam XVI-XVII Vekov. Kasean Baur.

Güneş, G., Ülker, H. İ.\& Karakoç, G. (2008). Sürdürülebilir turizmde yöresel yemek kültürünün önemi. 2. Ulusal Gastronomi Sempozyumunda sunulan bildiri. Akdeniz Üniversitesi Alanya İşletme Fakültesi, Antalya.

Keskin, E. Örgün, E \& Akbulut B.A. (2017). Gastronomi kavramının kelime ilişkilendirme testi aracılığıla analizi. Journal of Tourism Gastronomy Studies, 255-267.

McIntosh, A. (1996). Sociologies of food and nutrition. Plenum Press.

Ögel, B. (1982), Türk mutfağının gelişmesi ve Türk tarihi gelenekleri. Türk Mutfă̆ Sempozyumu Bildiriler. Kültür Turizm Bakanlığı Milli Folklor Araştırma Dairesi Yayınları, s.15-18.

Öztek, U. (2019). Selim İleri’nin eserlerinde yeme içme kültürü (Yayımlanmamış Yüksek Lisans Tezi). Hacettepe Üniversitesi Sosyal Bilimler Enstitüsü, Ankara.

Samsakçı, M. (2007). Türk kültür ve edebiyatında tuz ve tuz-ekmek hakkı. İstanbul Üniversitesi Edebiyat Fakültesi Türk Dili ve Edebiyatı Dergisi, 181-199.

Scarpato, R. (2002). Gastronomy studies in search of hospitality. Journal of Hospitality and Tourism Management, 9(2), 1-12.

Seyitoğlu, F. \& Çalışkan O. (2018). Akademik disiplin olarak gastronomi: kavramsal bir çalışma. Seyahat ve Otel Işletmeciliği Dergisi, 15 (3), 523-537.

Talas, M. (2005). Tarihi süreçte Türk beslenme kültürü ve Mehmet Eröz’e göre Türk yemekleri. Selçuk Üniversitesi Türkiyat Araştırmaları Dergisi, 1 (18): 273-283.

Tezcan, M. (2000). Türk yemek antropolojisi. T.C. Kültür Bakanlığı Yayınları. 


\section{EXTENDED ABSTRACT}

\section{Traces of Gastronomy in Philology Studies: Eating and Drinking in Kipchak Turkish Texts in Armenian Letter}

Gastronomy focuses on eating and drinking, which is the most basic need of human beings, in short, it is the science of preparing, serving and eating food in a way that includes culinary customs and traditions. Especially in recent years, gastronomy has attracted great attention. It is a comprehensive discipline that makes use of science and social sciences such as chemistry, physics, biology, psychology, sociology, history, philology, anthropology, economics, marketing, management and business administration.

It is possible to identify data that will contribute to issues such as food production, the storage, transportation, processing and cooking of food, the method of food, its taste, the special items used, the chemistry of food, its digestion, its physiological effects, the determination of the power and status of food in society, the religious, social, social and cultural aspect of food Data that will contribute to issues such as its relationship with folk medicine, witchcraft and ceremonies in the texts of Kipchak Turkish with Armenian Letters.

The texts in Kipchak Turkish with Armenian Letters, chosen as the sample of the research, include approximately 30 thousand pages, written in Kipchak Turkish between 1521 and 1699, on many different topics such as religion, history, law, literature, language, chemistry, using Armenian letters, in the north of the Black Sea. Kipchak Turkish with Armenian Letters originates from the Kipchak-Polovets languages of the Crimea region. It is similar in structure to the Thrace dialect of Karaim, Cuman, Kipchak Urum and Crimean-Tatar mountain dialect. These texts, which have an enormous volume of 30 thousand pages and a very rich content, are kept in libraries in Europe and Asia such as Vienna Mekhitarist Monastery, Vienna National Library, Venice Mekhitarist Library, Paris National Library, Wroclaw Ossolineum Library, Krakow Chartorysky Museum, Leiden University Library. Since the discovery of these texts, which are a great treasure in Turcology, and their announcement to the scientific world is very late, studies in this field are very few compared to other periods.

Looking at philological studies, gastronomy is mostly confined to the lexicological classification of food. In other words when the interdisciplinary studies of the fields of philology and gastronomy are considered, the types of words related to eating and drinking in a certain period or in certain cultures/nations and morphological or etymological studies related to them are understood. On the other hand, when not only the dictionary meaning of the words but also the context is given by the method of collocation in the texts in question; the cultural, social, religious, commercial and political meanings of the words will be displayed because evaluating the data in context is very important in terms of showing relationships between interrelated words in a particular field.

The scanning model was used as the method and Kipchak Turkish texts with Armenian letters were examined, the findings related to gastronomy were shared in the comments and discussion. Since the texts in question are very rich in volume, even food names contain enough material for thesis. For this reason, in this limited study, only selected examples that will give an idea about the subject headings are shared. 
The food, which was previously consumed in order to meet the basic needs of the body, has transformed the human being into a cultural entity and has made itself a cultural element over time. Since the most important element that can be evaluated within the scope of a nation's living culture is eating and drinking, every record and every data on gastronomy will take the work to be done in this field one step further. Gastronomy has a universal perspective but draws strength from national sources; so the worldviews, the philosophy of life, religious norms and social rules of the societies can be followed through their eating and drinking habits, studies that reveal the eating and drinking experiences of the Turkish society and the change and development of these experiences will add strength to the studies on gastronomy. 